\title{
Olive and olive pomace oil packing and marketing
}

\author{
By José Linares, Manuel García Palma, Mariano Iñigo, José Manuel García and Juan Berzosa
}

\author{
Grupo SOS - Carretera de Arjona, 4. \\ 23740 Andújar (Jaén) - Spain \\ Tel.: +34953515315 / Fax: +34953510065 \\ e-mail: jose.linares@gruposos.com
}

\section{RESUMEN}

Envasado y comercialización de aceite de oliva y aceite de orujo

En este artículo se describen los equipos e instalaciones industriales que utiliza el sector del aceite de oliva para el envasado de los aceites de oliva, los tipos de envases más empleados (plástico, vidrio, metálicos y cartón) y las diferentes tecnologías de llenado, taponado, etiquetado y embalado, así como las tendencias y nuevas tecnologías en función del material de los envases y la demanda de los mercados.

Se contemplan también aspectos logísticos como el paletizado, el almacenamiento y la expedición del producto terminado. El uso de modernas herramientas y sistemas de codificación como el EAN 128 permite el seguimiento del producto y la trazabilidad de los aceites envasados a lo largo de la cadena de distribución.

En la última parte del artículo, se indican cifras de producción y consumo de aceite de oliva en el mundo y en la Unión Europea. Se comentan especialmente las peculiaridades de los principales países productores de la Unión Europea: España, Italia, Grecia y Portugal. Finalmente, se hace alusión al consumo de aceite de oliva en países terceros, y más concretamente la evolución del consumo y las perspectivas de futuro en mercados emergentes como Estados Unidos, Australia y Japón.

PALABRAS-CLAVE: Aceite de oliva - Comercialización Embalado - Envasado - Trazabilidad.

\section{SUMMARY}

Olive and olive pomace oil packing and marketing

The paper describes the industrial installations and equipments used by the olive oil sector for olive oil packing, the different types of containers used (plastic, glass, tin, and carton), and the diverse technologies applied for filling, stoppering, labelling, and packing as well as the trend and new technologies developed according to the material of the containers and the markets' demands.

Some logistic aspects such as palletization, storage, and shipment of final products are also discussed. The use of modern tools and codification systems like EAN 128 permits to follow the product distribution and assure the traceability of packed oils.

The last part of the article includes the world and EU production and consumption of olive oil, paying special attention to the peculiarities of the main EU producers (Spain, Italy, Greece, and Portugal). Finally, the olive oil consumption in third countries is analysed and the consumption and its trend in merging markets like USA Australia, and Japan commented.
KEY-WORDS: Filling- Marketing - Olive oil - Packing Traceability

\section{THE BOTTLING OF OLIVE OIL}

The basic purpose of the bottling of olive oil is to easily identify the product and to guarantee that it is safely distributed to the consumer through the channels of distribution. Olive oil is a "live" product and its bottling requires the use of proper containers as well as additional materials and the appropriate construction of bottling machinery. It is equally necessary to take maximum sanitary and environmental precautions and to avoid any operation which may alter the natural qualities of the olive oil.

The key factors which may deteriorate the quality of olive oil are those which favor oxidation and rancidity with light, air, temperature and the presence of heavy metals being the most influential. All of these factors must be taken into account when selecting packing materials, in the bottling phase and during storage of the finished product.

\subsection{The Container}

The design and selection of the ideal container is of vital importance to the entire process. In effect, aside from fulfilling its traditional functions (to contain, protect, conserve, distribute and market), the container must be subject to several other considerations such as ecological (reuse and recycling of the materials), industrial (handling, resistance, weight, etc.) and sociological (design and product information).

The most common containers which are currently used in the bottling of olive oil are:

- Plastic. PET, transparent or opaque, is the plastic which is used almost exclusively for the packing of olive oil. Other materials such as PVC or high density polyethylene are no longer used primarily for technical, economic, and environmental reasons.

- Glass. The use of a glass bottle is very common. It can be either transparent or opaque. 
- Metal. The metal container or "can" is a traditional packing material which has long been used for olive oil. It consists of a container made of tin treated in its interior with a food resins varnish.

- Carton. The carton is the newest container in the olive oil industry and its application is due to its worldwide distribution and the success which has been obtained in the packing of other liquids (dairy products, juice, wine, water, etc.)
The container is made with very fine layers of plastic (polyethylene), paper and aluminium.

The use of one type of container or another, as primary packing material, comes with the acceptance of the advantages and disadvantages of each one, keeping in mind that the perfect container does not exist. In the table 1, we have summarized the primary functions of the containers used for olive oil.

Table 1

Functional analysis of containers for olive oil

\begin{tabular}{|c|c|c|c|c|}
\hline & Plastic & Glass & Tin & Carton \\
\hline \multicolumn{5}{|l|}{ PROTECTION } \\
\hline Resistant to invasion of foreign liquids and fumes & $X X$ & $X X X$ & $X X X$ & $X X X$ \\
\hline Insoluble (tasteless, odorless, without sediment) & $x X X$ & $X X X$ & $x X X$ & $x X X$ \\
\hline Resistance to the pressure of a gas dissolved in the oil & $X X$ & $X X X$ & $X X X$ & $\mathrm{XXX}$ \\
\hline Protection from light & & & $x X x$ & $x X X$ \\
\hline \multicolumn{5}{|l|}{ Shock resistant } \\
\hline \multicolumn{5}{|l|}{ MARKETING } \\
\hline May be attractively designed & $\mathrm{XXX}$ & $X X X$ & $\mathrm{XXX}$ & $X X X$ \\
\hline Allows for creative shapes and colors & $\mathrm{XXX}$ & $X X X$ & & \\
\hline Reviewing of the contents (visibility, transparency, color) & $X X X$ & $X X X$ & & \\
\hline \multicolumn{5}{|l|}{ SERVICE } \\
\hline Easily opened without utensils & $X X X$ & $X X X$ & $x X$ & $x X$ \\
\hline Guaranteed safety seal & $X X X$ & $X X X$ & $X X X$ & $X X X$ \\
\hline Leak proof and maintains its shape & $X X X$ & $X X X$ & $x$ & $X X$ \\
\hline Ease of handling & $x x x$ & $X X X$ & $x X$ & $x x$ \\
\hline Easy to pour & $x x x$ & $X X X$ & $x X$ & $x x$ \\
\hline Allows for measuring & $X X X$ & $X X X$ & $X X$ & $x X$ \\
\hline Visibility of remaining liquid & $X X X$ & $X X X$ & & \\
\hline \multicolumn{5}{|l|}{ DISTRIBUTION } \\
\hline Stable in the case or on the pallet & $X X X$ & $X X X$ & $X X X$ & $X X X$ \\
\hline Stackable & $\mathrm{x}$ & & $x X X$ & $x X X$ \\
\hline Portable and resistant & $x X$ & $X X X$ & $X X X$ & $X X X$ \\
\hline Occupies minimum space on the pallet & $x X$ & $X X$ & $X X X$ & $X X X$ \\
\hline Low weight & $X X X$ & $x$ & $X X$ & $X X X$ \\
\hline \multicolumn{5}{|l|}{ MANUFACTURING } \\
\hline May be manufactured at the bottling plant & $x X X$ & & & $X X X$ \\
\hline Easily adapted to the filling lines & $X X X$ & $x X$ & $X X X$ & $X X$ \\
\hline Permits high speed filling & $X X X$ & $X X$ & $x$ & $x$ \\
\hline Requires minimal investment & $x$ & $x$ & $X X X$ & $X X$ \\
\hline \multicolumn{5}{|l|}{ ENVIRONMENT } \\
\hline Takes up minimum space after use & $x x$ & & & $x x x$ \\
\hline \multicolumn{5}{|l|}{ Biodegradable } \\
\hline Made with recyclable materials & $X X X$ & $X X X$ & $X X X$ & $X X X$ \\
\hline Apt for reuse & & $X X X$ & & \\
\hline Easily incinerated. & $x X X$ & & & \\
\hline
\end{tabular}

Poor Fair $X \quad$ Good XX Excellent XXX 


\subsection{Stages in the bottling process}

The selection of a container implies differential changes in the selection of machinery as well as the design and function of the filling lines (Figures 1, 2 and 3). A filling line for olive oil packed in plastic containers is completely different from a line for metal ones. In general, the filling lines should be designed according to two basic criteria:

- The maintenance of a logical flow from the filling of the raw material to the application of additional materials and the outcome of the final product.

- The maximum utilization of available work space while keeping in mind possible future plans for expansion and or modification of the filling line.

The filling lines are made up of several specific machines which are linked to one another and maintain a logical working order depending on the different stages of the process. Regardless of the type of container used, the stages in the packing process are:

- Manufacturing, handling and transport of the container

- Filling and capping

- Labelling

- Packing

\subsubsection{Manufacturing, handling and transport of the container}

Plastic

As mentioned previously, PET is the most commonly, almost exclusively used among the containers available for bottling olive oil because of its technical, economic, and ecological advantages in comparison to other plastic materials.

The PET container can be fitted to the filling line in two different ways:

- Manufactured and delivered by a supplier as an additional material

- Manufactured on sight at the bottling plant.

When the container is delivered to the bottling plant as additional material, the feeding of empty containers to the filling line should be designed manually as well as automatically (depalletizing and or placement of containers) in accordance with the nominal speed of the line.

Manufacturing PET containers at the packing plant has great technical, economic and logistic advantages. Currently, there are two different procedures for the onsite manufacturing of PET containers.

- Integral manufacturing in two phases (injection + blowing) directly from PET

- Manufacturing in only one phase (blowing) starting from PET preforms
The advantages and disadvantages of one or the other of these procedures are related to the nominal speed of the filling line, whether or not there are filling lines operating simultaneously, and the type of handling the container will undergo after it has been manufactured:

a) Storage in tanks + placement of containers + transport of empty containers

b) Palletizing + storage + depalletizing + transport of empty containers

c) Manufacturing of PET containers in line with the filling machines.

Options a) and b) are the ones which are currently implemented in the majority of olive oil bottling plants where the containers are manufactured on site. These options have the drawbacks of a limitation on the minimum weight of the container so that it may be stored in tanks or palletized without being damaged along with the requirement of installing empty container inspectors and or blowers prior to the filling phase in order to avoid the presence of foreign contaminants in the interior of the containers.

The newest trends in the industry are moving towards option c) which is the installation of the machinery necessary to manufacture PET as one more element in the filling line. Single phase PET blowers phase, are the ideal machines for this future proposition for olive oil bottling plants because of their simplicity, wide range of manufacturing capacity and their ease of incorporation into the rest of the machines which make up the filling line. Their economic, technical and sanitary advantages may be summarized in the following points:

- The limit on the weight of the container is only defined by its shape and future use, eliminating the need for minimum weight demands stemming from the storage and handling of the empty container.

- The absence of contamination or foreign bodies in the interior of the container is guaranteed. The pre-forms, after prior inspection, are blown, the container is hung by its neck and driven directly to the filler without undergoing any intermediate handling.

- The elimination of the concepts of "the manufacturing of containers" outside the bottling plant, storage in tanks or on pallets, depalletizing and ordering of empty containers, inspection/blowing of the containers and the conventional transporting of empty containers are all eliminated.

- Substantial economic savings are derived from the reduced surface area needed for the storage of empty containers. Once the containers are blown, they are bottled immediately, with an accumulation of $2 / 3$ minutes between PET blower and the filling machine.

- The modern system of transporting the bottle from the blower to the filler by hanging it by its 
neck eliminates all the previous problems of deterioration and poor automation associated with the traditional system of transporting containers on belts.

- Additional economic savings are derived from a more rational employment of the labor force in the entire bottling operation.

\section{Glass}

The glass container is manufactured and palletized at the glass factory and supplied to the bottling plant as additional material. The bottling line should be prepared for reception and manual or automatic (depalletizing) feeding in function with the nominal speed of the filling machines. In order to guarantee the absence of foreign contaminants in the interior of the container, it is absolutely necessary to install machines for the blowing and vacuuming of inverted bottles prior to filling. The newest trends are moving towards the electronic inspection of the walls and bottoms of the bottles by means of artificial or x-ray vision followed by the automatic elimination of the containers which do not comply with the standards previously set in the computer of the machine.

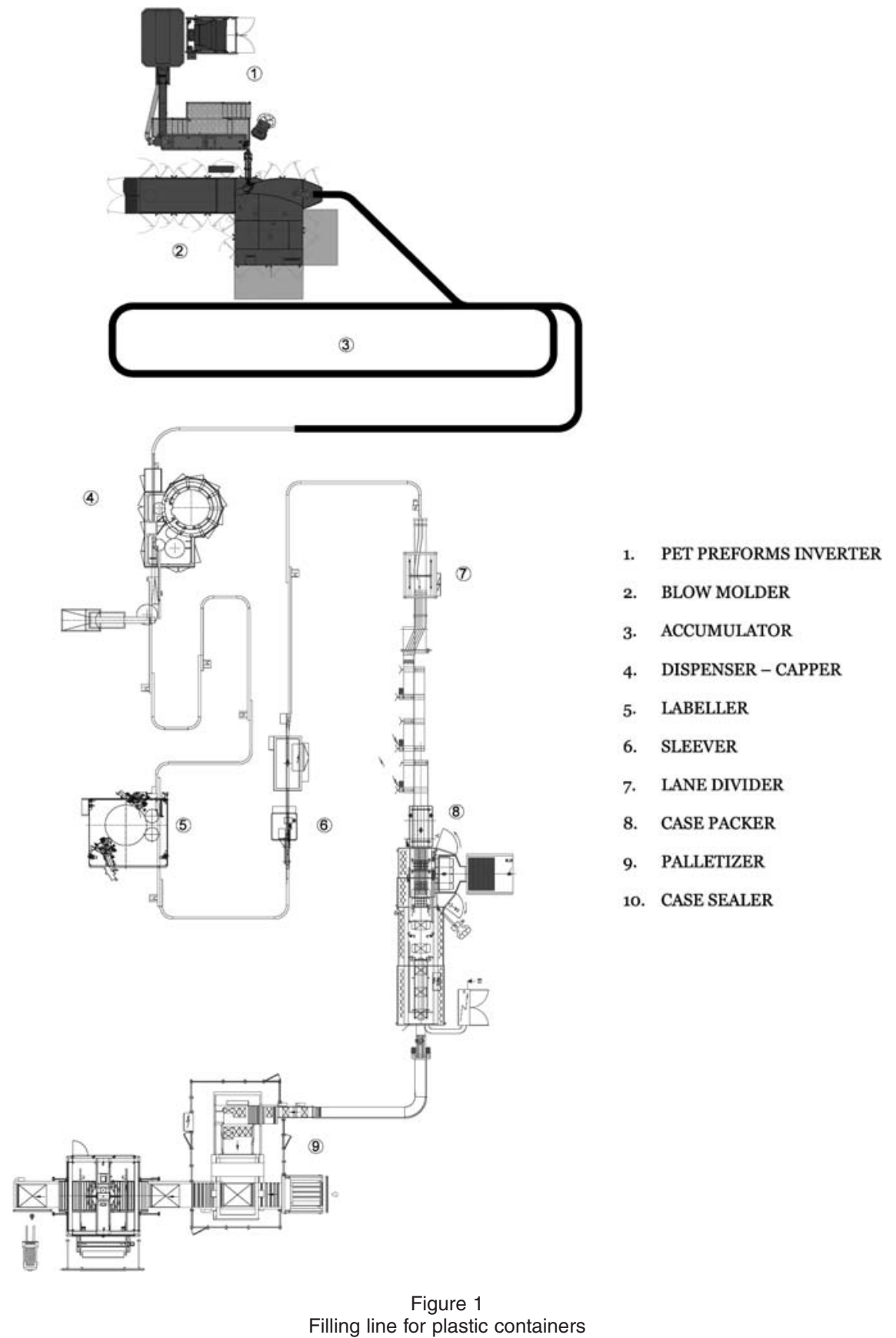




\section{Metal containers}

In the same way as glass bottles, the classic "tins" are manufactured and palletized at the metal factory and supplied to the bottling plant as additional material. The design for the reception and feeding of the empty containers is similar to that described for the filling lines of glass containers. The metal container may be made in two different ways:

a) Bottom and top closed at the metal plant with an orifice on the top for future filling and capping.

b) Only the bottom is closed at the metal plant and the top is closed at the bottling plant.

The advantages and disadvantages of each one of these methods will be explained further on when referring to the filling and capping stages. In the case of receiving the tins according to method $b$ ) it is absolutely necessary to carry out the inverted blowing of the container in order to prevent the presence of foreign contaminants after filling and closing the container.

\section{Carton}

This type of packaging has the unique advantage that the container is formed at the same time as the filling operation on the same machine through bobbins which are supplied to the bottling plant as additional material. One of the great advantages of this type of container is the absolute guarantee of hygiene and purity during the formation and filling of the container.

\subsubsection{Filling and capping}

The filling and capping phase is one of the most decisive in the entire process and the arrival of the product to the consumer with the required quality and quantity depends on the efficiency of this step.

The actual content of oil inside the containers is verified and registered in real time. This control is carried out not only to comply with legislative demands but also to guarantee an economic production from the filling operation.

\section{Plastic}

For the filling of PET containers, the entire range of filling machines which are currently used for the bottling of liquids may be employed.

- Ponderal

- Volumetric

- Precision level (vacuum or electronic)

The precision levels guaranteed by the makers of the different types of filling machines are similar as long as the working conditions comply with minimum recommended requirements. Level fillers require the temperature of the oil to remain homogeneous and constant at around $20^{\circ} \mathrm{C}$. It is equally important that the weight of the container be homogeneous and free from large variations. For the Volumetric fillers the temperature factor is crucial and the oil must be maintained at $20^{\circ} \mathrm{C}$. Ponderal fillers are unaffected by the weight of the container or the temperature of the oil, although it is recommended that the oil be maintained at $20^{\circ} \mathrm{C}$ so that capacity problems do not arise due to a change in the density of the oil as its temperature changes. PET bottles should be closed with a high pressure plastic cap. A suitable cap is one which has the following characteristics:

- Tamper proof

- Tear-tab

- Safety sealed

- Leak proof

- Easy to open

- Drip proof

- Spill proof

- Easy to pour

The filling and capping systems are usually composed of a single unit. A modern, triblock system is installed so that the blowing, filling and capping are all carried out on the same machine.

\section{Glass}

The machines used for glass are the same type mentioned above for PET. The most common are the fillers largely because of their weight distribution and their tolerance for the thickness of the walls of glass containers. Level fillers overcome these problems and result in a uniform bottling with the same level of liquid in each container.

Obviously, maintaining a constant level in all glass containers does not automatically guarantee an excellent filling curve keeping in mind an average margin for error. The important thing is the image and presentation which must be compatible at all times with consumer demands and the guarantee of actual content of oil as established by the legislation as well as an economic production from the filling process.

As a solution to the constant level problem, ponderal and volumetric fillers have incorporated a levelling station between the filling and capping phases with the objective of bottling all glass containers to the same level. This operation requires a control of the unit excess capacity of the containers so that a homogeneous level may be established at the levelling station which meets legislative demands.

The caps used for glass containers are usually plastic (pressure) or metal (pilfer). Both types of caps must meet the minimum requirements as commented above for plastic caps.

Sometimes shrink wraps are placed on the neck of the bottles with the double objective of decorating the bottle and offering a safety seal in addition to the cap.

\section{Metal containers}

A great majority of the filling machines used for bottling olive oil in metal containers are the volumetric type. 

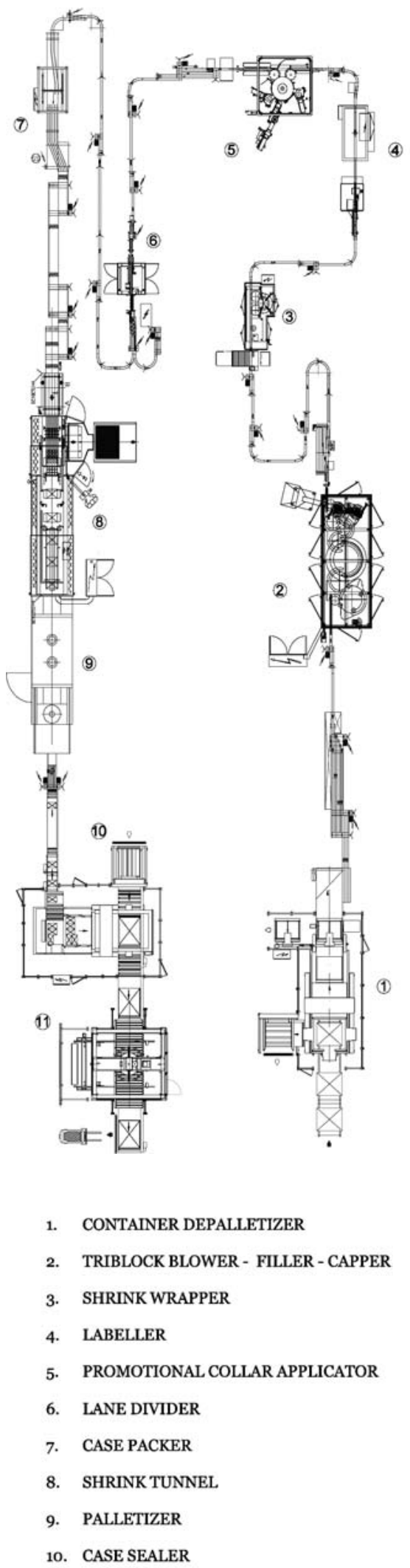

Figure 2

Filling line for glass containers
The closure of the tin is subject to the type of container which is supplied by the metal plant, as previously mentioned.

If the container supplied is closed on the bottom and on the top, the filling valve is inserted into an opening on the top. The cap is then fitted by pressure. This system has the drawback of not allowing for inverted container blowing so that there are no foreign contaminants in the interior of the container after it has been filled and capped.

When the container is supplied with only its bottom closed, the closure of the container is carried out with a machine specifically designed for this purpose. In addition to allowing the inverted blowing of the container in an affective way, the advantage of this system is being able to fit a spout cap or a flat cap according to market demands.

\section{Carton}

As pointed out previously, the carton is the newest design in containers which has been incorporated into the olive oil bottling industry. The phases of formation of container, filling and capping are carried out simultaneously on the same machine with all the advantages that can be derived from this system. The first commercial presentations for olive oil were hardly distinguishable from the rest of the containers we are familiar with in this format for different liquids (milk, juice etc.). The absence of a pouring spout was a disadvantage in the first containers which has since been remedied with new designs specifically for the bottling of olive oil. The pouring/measuring spout is fitted to the container by means of a specific machine which applies the spout and fixes it to the carton, once it is closed, using a hot adhesive.

In general, we can point out that the latest trends in the olive oil bottling industry are moving towards the introduction of nitrogen with the objective of improving the preservation of the oil along with the prevention of the collapse of PET containers.

The function of nitrogen is to avoid the oil coming into contact with air by removing it from the tops of the bottles. Nitrogen can be used in gas or liquid form.

In its gas form, nitrogen is injected into the filling valves and into the sealed tank of the filling machine until a complete saturation of the gas into the liquid is achieved.

In its liquid form, nitrogen is incorporated by doses between the filling and capping phases. It is important to first calculate the final pressure the container can tolerate in order to avoid breaking or deforming of the bottles.

\subsubsection{Decorating the container}

The bottle is decorated with the objective of presenting an image to the consumer and informing about the product. 


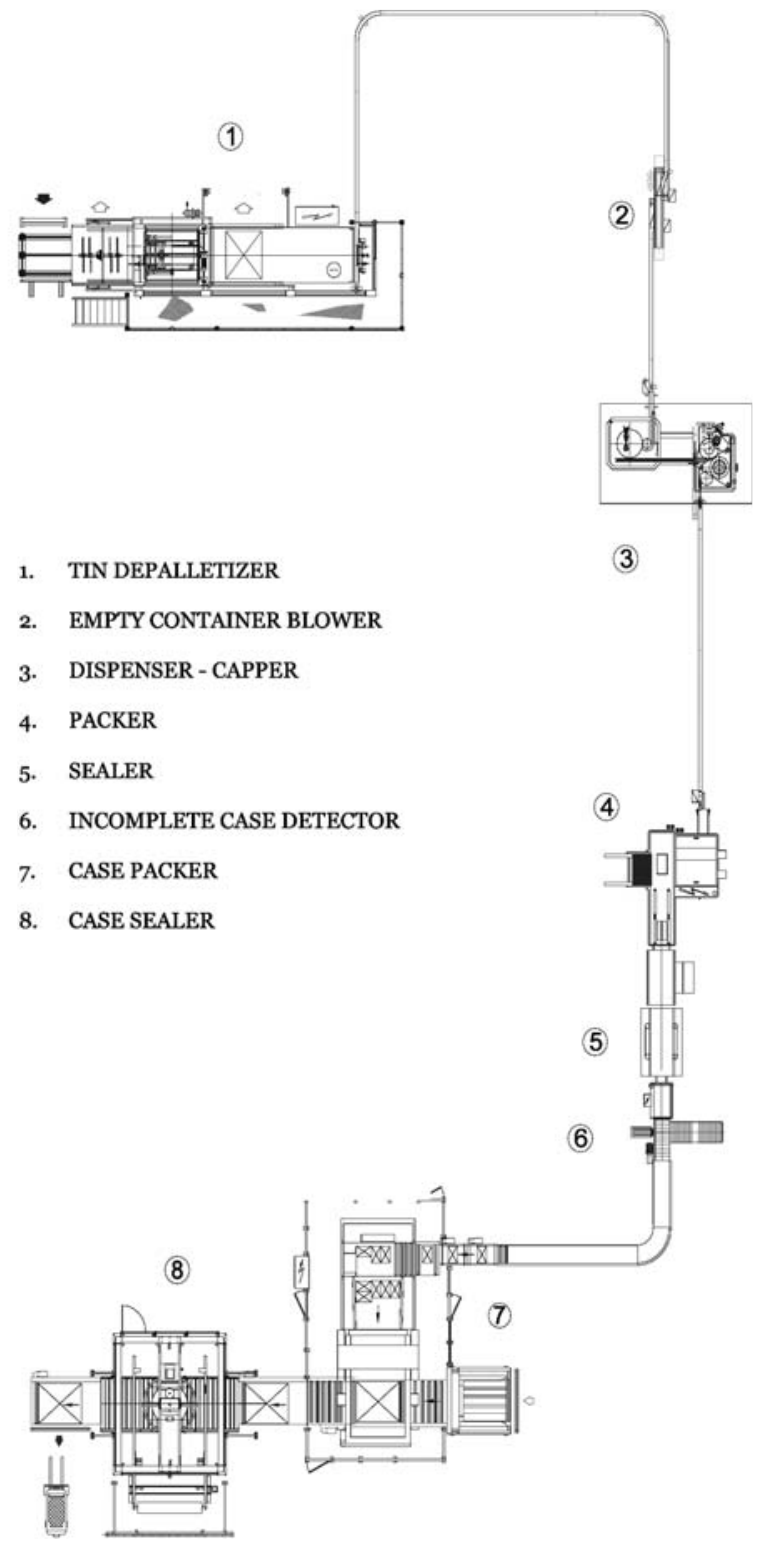

Figure 3

Filling line for tins

\section{Plastic}

The decoration of PET containers is carried out with labels which may be self adhesive or applied with cold or hot glue. The reasons for choosing one method or another are related to the desired design and quality, the speed and frequency of changes in the format of the labels and the estimated cost of the labelling operation.

\section{Glass}

The machinery and the type of labels frequently used for the labelling of glass bottles are the same as those used for PET containers.
The latest trends being developed for glass and plastic containers are the plastic "sleeve" type label (PET, PVC, PP).

The "sleeve" labels are supplied in the form of a continuous bobbin and after being slipped onto the bottles, they are retracted in an electric or vapor oven until they are perfectly adapted to the contour of the container. The application of "sleeves" offers endless design possibilities for the complete or partial dressing of the containers.

The use of promotional labels of the "detachable", "hanging" or "tie" type on glass or plastic olive oil containers is becoming more and more common. When low speed filling lines are used (fewer than 2000 containers/hour), the placement of these labels may be done manually. However, if a higher speed filler is used, then it is necessary to resort to an extraordinarily precise machine which has been designed exclusively for this purpose.

\section{Metal containers}

The metal container provides the advantage of being decorated in its entirety. The metal plant supplies a lithographed container while the cap is normally left to personalize the tin by means of "inject" markers which contain information on the date and lot number as well as the client the product is being sent to.

\section{Carton}

Just like in the previous case, the entire container may be decorated. The bobbins which the cartons are formed from are supplied after previous printing and therefore offer infinite design possibilities.

\subsubsection{Packing}

As a general rule, the design for the end of the filling line is moving towards systems which permit versatility both in the packing type (in cases, on trays, on trays with film) as well as the number of containers which make up a group.

The computerized management of production, storage and distribution require significant changes in the ends of the filling lines and in the packing lines. The massive employment of radio frequency systems in the management of warehouses and the expediting of merchandise has made the adherence of the pallets to code EAN 128 necessary. In order to automate the generating and application process of code EAN 128, the cases must be perfectly identifiable by a scanner through the information contained in the DUN 14 code on the case. The current trend is to place automatic printers at the end of the line which, after reading the DUN14, produce an EAN 128 label which is placed on the packing unit (pallet). 


\section{LOGISTICS}

\subsection{Bulk shipping}

Due to the imbalance which exists among olive oil producing countries, concerning the different levels of production, consumption and export needs, a large amount of olive oil is shipped in bulk. This movement is carried out mainly by boat, but also in tanks and shipping containers.

On the other hand, companies located in nonproducing countries like Japan or Brazil import olive oil in bulk to later bottle and distribute it in their respective countries.

\subsection{Bottled Oils. Packing}

In this section, we will concentrate on the logistics surrounding the final product, bottled and ready for consumption.

According to current legislation, the retail of olive oil and olive pomace oil in the area of the EU establishes that the final product must be presented to the consumer in containers with a maximum capacity of 5 liters.

The unit of consumption or primary packaging is defined as the combination of the container and its contents, properly labelled according to current legislation and with an opening system which is no longer resealable once it has been opened.

Secondary packaging, which consists of two or more containers which make up a single unit, is hardly significant in the commercialization of olive oil. The most common format for plastic, glass, tins or cartons is tertiary packaging.

In general, the retail unit or tertiary packaging which is sold to clients is the B-1 cardboard box or "wraparound" system. The contents of this unit vary according to the size and type of container.

New demands on distribution, mostly by large department stores, call for the packing of PET bottles on trays which are ready for display and shipped on pallets or $1 / 2$ pallets. The cardboard trays are placed directly on the pallet or $1 / 2$ pallet in stacks of four. The trays are then wrapped in plastic shrink wrap with an appropriate shape and sufficient thickness to insure the successful storage, shipping and distribution of this modern packaging system.

The packing system used for glass containers is similar to the one used for plastic. When B-1 cardboard boxes are used, it is normally necessary to place cardboard separators between the bottles in order to prevent breaking during storage, shipping and distribution. If the "wraparound" system is used, separators are usually no longer necessary.

Because of the fragile nature of glass containers, the shrink wrap packaging system is not advisable.

The most common packaging system for tins and cartons is the cardboard box. However, new designs for carton containers of the "prism" type include a pouring spout which is placed on the top of the container and require packaging in cardboard boxes because stacking them onto pallets may cause damage to the spout.

\subsection{Pallets and containers}

Even though the boxes which make up the layers on the pallet are slightly adhered to one another by applying glue to the box tops, the pallets are usually wrapped in a transparent plastic film to make sure that the merchandise does not slip off the pallets during storage, loading or shipping.

For smaller productions, this wrapping procedure is carried out immediately before loading using individual wrapping equipment, one for each load. Nevertheless, on a higher industrial scale, this operation is usually done at the end of the filling line, by means of a high capacity installation with high level automation that wraps each pallet as it comes off the production line. These prewrapped pallets are then stored until they are shipped.

For logistic purposes, the shipping unit most commonly used in the bottling industry is the standard European pallet which measures $800 \mathrm{x}$ $1.200 \mathrm{~mm}$ and consists of several stacks of boxes with a variable height depending on different logistic requirements.

The success of the European pallet is due to its dimensions since its length (1.2 meters) is a little less than half the maximum width of regulation trucks (2.5 meters) which makes for efficient use of the loading capacity of vehicles.

However, in english spoken countries, the 1.000 $x 1.200 \mathrm{~mm}$ pallet is used.

Exporting from the producing countries of the Mediterranean basin to other countries, including overseas destinations, is usually done in $40 \mathrm{ft}$. containers with a capacity of 25 European pallets or in maxi-cap containers which are 12.5 meters long and can hold 30 pallets. However, the most commonly used is the $20 \mathrm{ft}$. container which has the advantage of being more manageable than the others but requires manual handling. The $20 \mathrm{ft}$. containers are usually fully loaded with bulk containers in the interior and the empty spaces filled with air bags in order to avoid shifting of the merchandise during transport.

\subsection{EAN 128}

Large industries in olive oil producing countries, especially in the European Union, use effective software tools and coding systems, which is the case of EAN 128, a common demand of modern distribution chains.

EAN 128 is a standard coding system which uses international bar codes for the identification of merchandise in logistic terms, but not in detail. It is fundamentally used for the identification of shipping units since it permits:

- The identification of the product and its groupings, supplying additional information 
such as lot number, manufacturing, bottling or expiration dates, number, size and net or actual weight of the containers, etc, all of which mean a substantial increase in the information which is automatically available to businesses.

- The guarantee of traceability of the product through the supply chain until it reaches large logistic centers or distribution platforms.

The structure of EAN 128 is open and allows for modular application in order to comply with the needs of different companies so that it can be used to improve the flow of merchandise and the information available about the packing process, increase productivity, reduce errors and reduce documentation times by means of the automatic capturing of the information contained in EAN 128 through optic sensors.

The label may be designed according to the information which suppliers wish to provide.

The use of EAN 128 focuses mainly on the logistic process of the handling of merchandise and information is relayed in code via EDI (Electronic Data Exchange).

The EAN 128 identification system is presented through bar codes which permit the capturing of information automatically using optic sensors. The code is represented by so-called "Application Identifiers" which allow all the information to be included on the label to be classified in standard form.

Application Identifiers are numeric prefixes of 2 , 3 or 4 digits which are presented in parentheses in order to give more precise meaning to the following information contained in the bar codes. The range of data they refer to will always be found directly after the "Al" prefix. Currently, there are more than 100 standardized Application Identifiers.

An important characteristic of these identifiers is their concatenation, which offers the possibility of linking several pieces of information in a single code.

The EAN 128 code consists of the most complete alpha-numeric symbol system currently available. Its name derives from its capacity to translate all 128 ASCII characters into code.

The general structure of the EAN 128 symbols is of the following type:

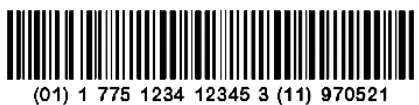

- (01) is the "Application Identifier" which indicates that the code which follows is a DUN-14.

- 17751234123453 is the DUN-14 box code of the packaging units included on the pallet.

- (11) is the "Application Identifier" which indicates the date of manufacturing.

- 970521 is the manufacturing date of the product contained on the pallet.
Among the different Application Identifiers available is the $\mathrm{Al}(00)$, also known as the SSCC (Serial Shipping Container Code).

This element of the EAN 128 label is the key to efficient delivery. The meaning of $\mathrm{Al}(00)$ is a personalized number (similar to the licence plate on a vehicle which is associated with the delivery unit (usually the pallet) and as such, permits differentiating among identical units. This registration number corresponding to the delivery unit contains computerized information on the content of that specific unit, its characteristics and its delivery specifications.

The SSCC must be only assigned by the company which prepares the delivery unit. In addition, it is valid for any shipping unit, be it standard or not, homogeneous or heterogeneous.

The SSCC is not usually used in the grouping (boxes) contained in the delivery unit. A box may be identified by an SSCC only in cases where a single box may be a logistic unit in itself and therefore require individual tracing.

\subsection{Traceability}

In the year 2002, the European Parliament passed Regulation (CE) 178/2002 which establishes the principles and general requirements of food safety and traceability, creating, at the same time, the European Authority on Food Safety.

This regulation defines traceability as "the ability to trace and follow a food, feed, foodproducing animal or substance intended to be, or expected to be incorporated into a food or feed, through all stages of production, processing and distribution."

The implementing of a tracing system has the objective of establishing a method for evaluating the traceability of a product from its origin (raw material) to the consumer (packaged product) with the aim of assuring the safety and quality of the product.

The traceability of the production process requires the implementation of the following steps:

- Individualized identification of all phases of the complete process.

- Automated process of data capturing.

- Information system accessible at all steps.

The concept of traceability should not be limited to the tracing of the product but should extend to all of its components. Therefore, the concept of "under water tracing" is born, also known as "customer tracing" or "supplied" in which the management and follow up are done thanks to the coded information contained in the EAN 128 label.

This traceability allows the bottling plant to know which products have left their warehouse and to which client they have been sold. At the same time, it allows the distribution companies to know in which warehouse or platform the product they have just purchased may be found, including the location (point of sales) of each product batch. 
If we further include "internal traceability or process traceability" to the additional information provided by the supplier, what we call "above water traceability" or "absorbed traceability", allows us to obtain complete and thorough information on the product being supplied.

\subsubsection{Traceability Applications}

Traceability allows for the following of a product through the entire supply chain. At each link of the chain inspection should be carried out in order to know the origin, location and route of a product: every link is important.

It is necessary to employ a common language (EAN labels and data via EDI) which permits the exchange of information (invoices, order forms, delivery notices, etc) among all parties involved in the transaction and the automatic capturing of information according to a similar scheme to the one explained in the figure 4 :

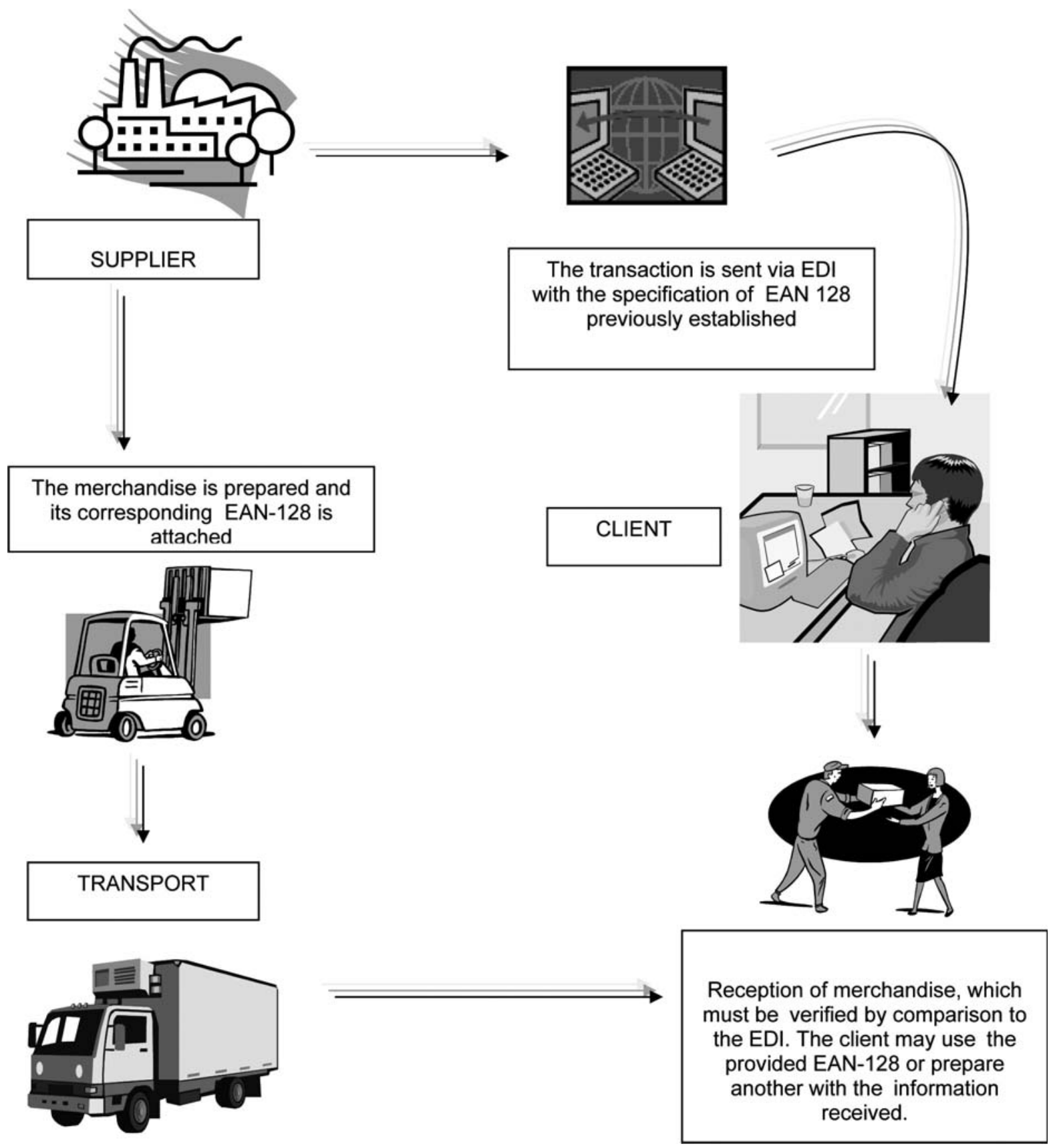

Figure 4

General outline of merchandise and information flow. 


\subsubsection{Traceability Systems}

There are two basic systems which traceability may be based on: paper and bar codes. Carrying out traceability in a manual manner, with order forms, invoices, lots, shipping notes, etc can cause problems. It can be done well but searches and inspections can be complicated and time consuming.

An adequate system requires agility, speed and precision, especially in cases of food alert. On paper, data may be found but it lacks information. The amount of paperwork involved in a large company is overwhelming and a data search cannot be agile if it is done manually. Therefore, it is recommended to change from paper to an electronic system. At the same time, companies may take advantage of the opportunity to modernize the mechanisms of these systems.

The bar code may solve many of these problems even though it is not infallible and if it is not used properly it may be time consuming. So commercial coding must be unique and never ambiguous in order for traceability to work.

There are systems which use GDS and EPC technologies which help to solve some problems like out of stock or excess inventory. Identification by radio frequency (RFID) has been one of the most important recent innovations since the codes on products, unique to each individual article, case or pallet are printed on a label and read by a radio frequency sensor.

It must be kept in mind that the implementation of this type of system does not require a structural revolution in the warehouse, although it does require changes in working habits.

Radio frequency may be installed in warehouses with conventional shelving, drive-in shelves or on automatic silos.

\subsubsection{Types of Warehouses}

Conventional shelving as well as the drive-in type are storage systems in which the merchandise is placed on shelves of easy access, one unit deep, in the first case, and more than one unit deep with aisles and diverse levels in the second case.

In another, different line, automatic systems can be found which consist of storage racks with a much greater height than the previous two and with a larger number of storage levels, which can have different depths accessible to automated transelevators with telescopic forks, capable of locating material with a frequency of more than 500 pallets in a normal 8hour working day.

A warehouse which is managed by transelevators has numerous advantages. The main one is to guarantee absolute traceability of all units up to their final destination. Other advantages are obtained, such as reduced workload and increased work space, since it is taken up in height, reducing the area occupied in the warehouse and the possibility of knowing, at any time, the location of the inventory in stock. Another great advantage is that such systems are automated and are therefore capable of maintaining productivity 24 hours a day, 365 days a year.

\section{CONSUMPTION AND MARKETING OF OLIVE OIL}

\subsection{Introduction}

The consumption and commercialisation of olive oil go back as far as the beginnings of western civilization. Even today we can find evidence in places like Rome, where an artificial hill, called Testaccio, was created out of the clay jars used to hold olive oil made in Southern Spain (Betica) to supply the Metropolis. This supply lasted from the first century B.C. up to the final collapse of the roman empire in the fifth century A.C.

In a more contemporary context, it should be pointed out that the consumption of olive oil has undergone constant growth over the last 45 years, especially during the 90 s and up to the present.

The purpose of this chapter is to give a brief description of the most important markets and their evolution from a marketing perspective based on a brief analysis of the four variables of marketingmix ${ }^{1}$, commonly known as the "4 P's":

- Product: includes the characteristics of the product as well as its presentation (packaging), with special emphasis on aspects like traceability.

- Price: where we will point out the elements that make up the varying price levels in different markets.

- Place: makes reference to all the necessary activities involved in getting the product to reach the consumer.

- Promotion: understood in broad terms as the joint instruments which may be used to promote the product in question, which includes advertising and public relations among other things.

\subsection{World Consumption}

From the 1960s up to the present, olive oil consumption and production worldwide have more than doubled, experiencing an accumulated growth of more than $21 \%$ each decade according to the information provided by the International Olive Oil Council (I.O.O.C.).

${ }^{1}$ McCarthy, Jerome, was the first author to use this tem in Basic Marketing: A Managerial Approcah, Richard D.Irwin Inc., Homewood, Illinois, 1958. 
In order to get more precisely conclusions about trends in both elements, and to eliminate the possible effects of an unstable olive crop (alternating a good production with

a poor one in a consecutive manner), together with the annual results, an additional historic series has been added with the variable averages of three seasons.

The Figure 5 shows how the trends in production as well as worldwide consumption are clearly rising, with consumption slightly superior to production.

If, instead of using annual results, we use the data which corresponds to the variable averages of the three seasons (Figure 6), a considerable improvement in the correlation of the coefficients of both trends can be seen, especially in production as a result of the elimination of the effects of crop instability.

In this way, it is been proved how it is the limitations of a scarce production of olive oil which limit greater consumption. In other words, the worldwide demand for olive oil is greater than the offer.

Further proof can be found in the fact that, following the increase in supply due to production

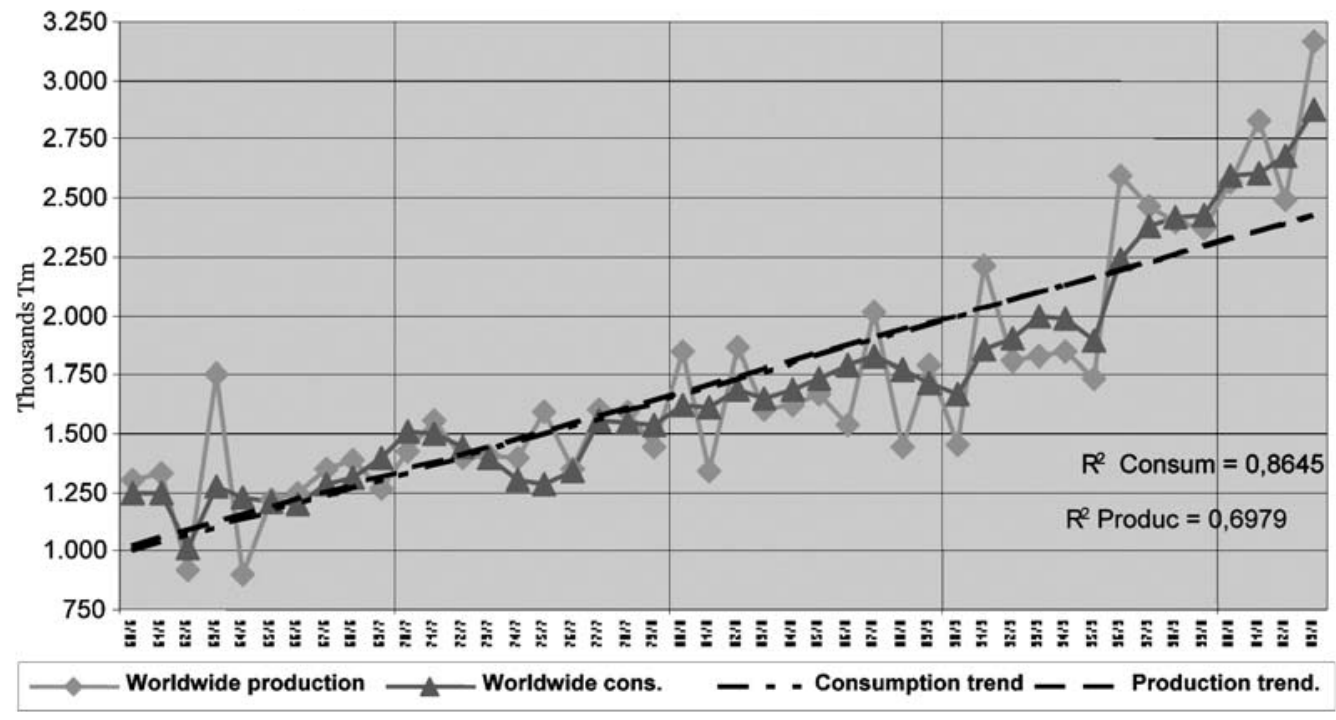

Figure 5

Worldwide Production and Consumption of Olive Oil Source: I.O.O.C.

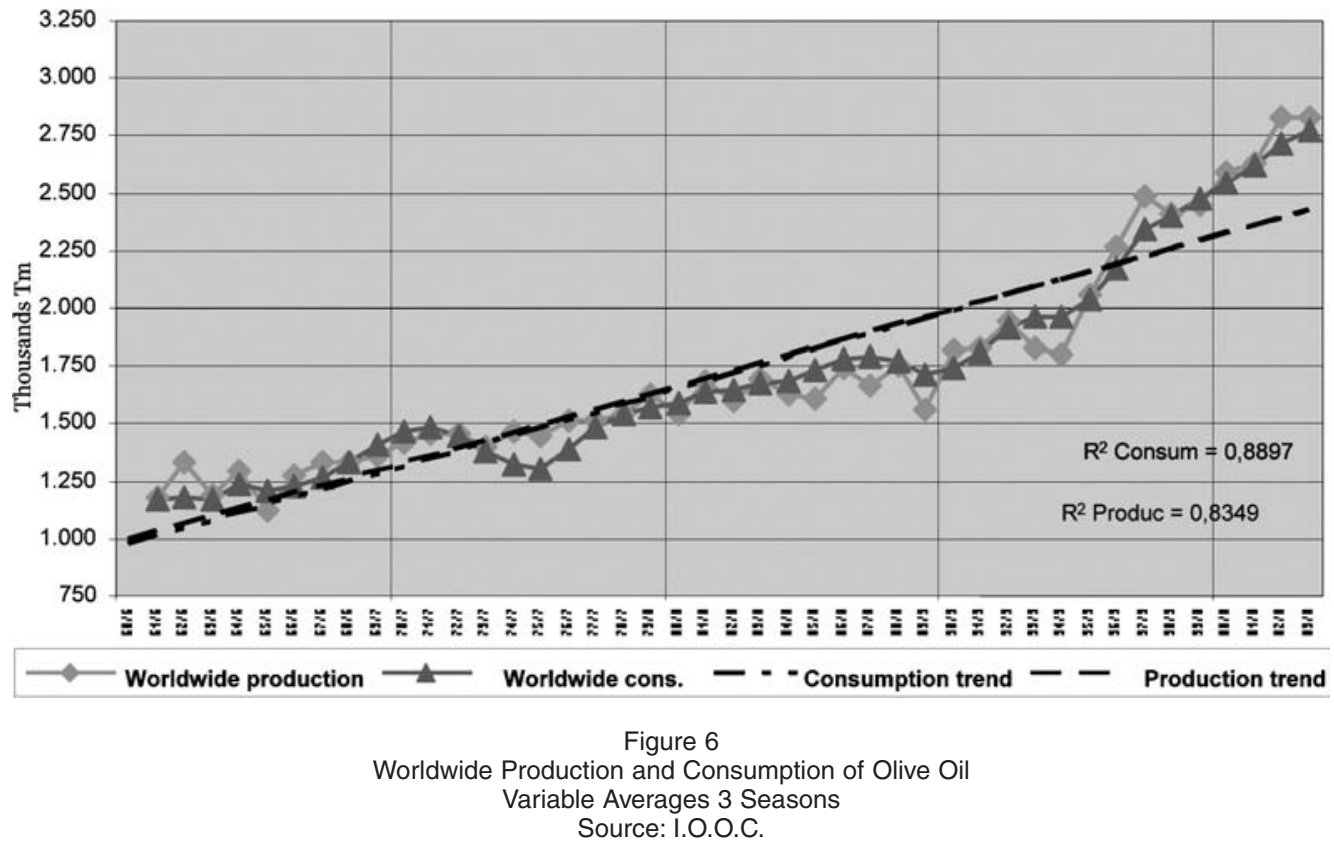


growth in Spain towards the end of the 90s - which in the last six seasons has represented a growth of almost $40 \%$ of the world's total production - the demand for this product has also increased. The key elements to such growth have been:

- An increase in land area dedicated to olive tree cultivation which has gone from 1.897,3 thousands of hectares in 1985 to $2.144,0$ thousands of hectares in 2002 (source: Spanish Ministry of Agriculture -MAPA).

- The improvement in agriculture techniques, which included the installation of irrigation by droplet, an increase in the number of trees per hectare, a better selection of olive variety, the application of insecticides, etc.

- As a consequence of the previously noted factors, a substantial increase in the productivity of the Spanish olive has gone from 0,98 metric tons per hectare of olives for oil in 1985 to 1,8904 metric tons per hectare in 2002 (source: Spanish Ministry of Agriculture -MAPA).

However, while a growth increase in the worldwide consumption has been seen in the traditional olive producing countries of the Mediterranean basin, the largest increase in consumption has been registered for nonproducing countries such as Holland, Germany or Great Britain within the European Union; and in countries on other continents such as Japan, Australia, or the United States.

The causes for such increase may be explained, in summary, by the following factors:

- A growing worldwide concern for health and the consumption of healthy fats which in recent times has been added to the traditional debate over saturated versus nonsaturated fats and the negative presence of trans fats.

- The substantial growth in the consumption of natural foods.

- The spread of information about the virtues of the Mediterranean diet, and especially olive oil.

Promotional campaigns, on an institutional basis (European Union, I.O.O.C., etc) as well as private (companies) in the last 20 years, especially in nonproducing countries.

\subsection{Olive Oil in the European Union}

Within the fifteen member states of the European Union, prior to the recent amplification undergone in 2004, when referring to olive oil, we must distinguish between the producing countries of Spain, Italy, Greece and on a lower scale, Portugal; and the nonproducing countries, which would be the rest. France has a nominal production, entirely insufficient to supply its growing demand

In the following section, a brief description of these markets will be made with special emphasis on Spain and Italy as they make up the majority of consumers in the world.

\subsubsection{Olive oil in Spain}

The Spanish bottled olive oil market is a mature market in which large variations in total volume are related to elevated increases or decreases in its price. In this sense, the demand for olive oil in Spain is practically inelastic.

One of its specific characteristics is in reference to its segmentation based on the type of products found on the market, always in accordance to Regulation (EC) $\mathrm{N}^{\circ} 1019 / 2002$ of the Commission of June 13 , 2002 on the norms of the marketing of olive oil. Said segments, clearly differentiated, are the following:

- Extra virgin olive oil.

- Virgin olive oil.

- Olive oil with a mild flavor: made up of between 80 and 90 per cent refined olive oil, with the other 10 or 20 per cent coming from virgin or extra virgin olive oil. This oil has a maximum acidity of $0.5 \%$.

- Olive oil with an intense flavor: consisting of between fifty and sixty per cent refined olive oil with the rest coming from virgin or extra virgin olive oil. Its acidity level is situated between 0.6 and $1 \%$ which lends a more intense color and flavor to the oil.

At the same time, the greatest evolution in what is referred to as the product per se has been aimed at the oils of the extra virgin type. By means of the progressive development of the "Protected Designation of Origin" (PDO) and Geographic Indications as well as pure varieties, extra virgin olive oil has undergone a similar trend to the one established years back in the wine industry. Nevertheless, these new products, positioned in an elevated price range, continue to be hardly significant in terms of volume.

In recent years, there has been a continuing growth in the consumption of extra virgin olive oil in detriment to the other types, especially virgin olive oil (Figure 7).

Another peculiarity is the generalized use of plastic containers in all olive categories, including extra virgin. Plastic makes up for $96 \%$ of the total commercial volume. Of the rest, $3 \%$ corresponds to glass bottles used for extra virgin olive oil from the high price ranges (organic, monovarietal, PDO and similar), and the final $1 \%$ corresponds to the traditional tins (source: Scantrack Nielsen).

The biggest changes which the bottling industry has undergone in recent years have basically consisted in the complete substitution of PVC, which was used throughout the industry during the beginning of the 90 s, for PET containers due to their ecological and recycling benefits; and in the significant improvement in capping, which has gradually incorporated better and better leak proof systems.

The general use of plastic containers for olive oil, as well as seeds oils, is influenced by the fact that this product is considered to be a product of primary necessity, which, at the same time, has made their use an advantage for consumers as 


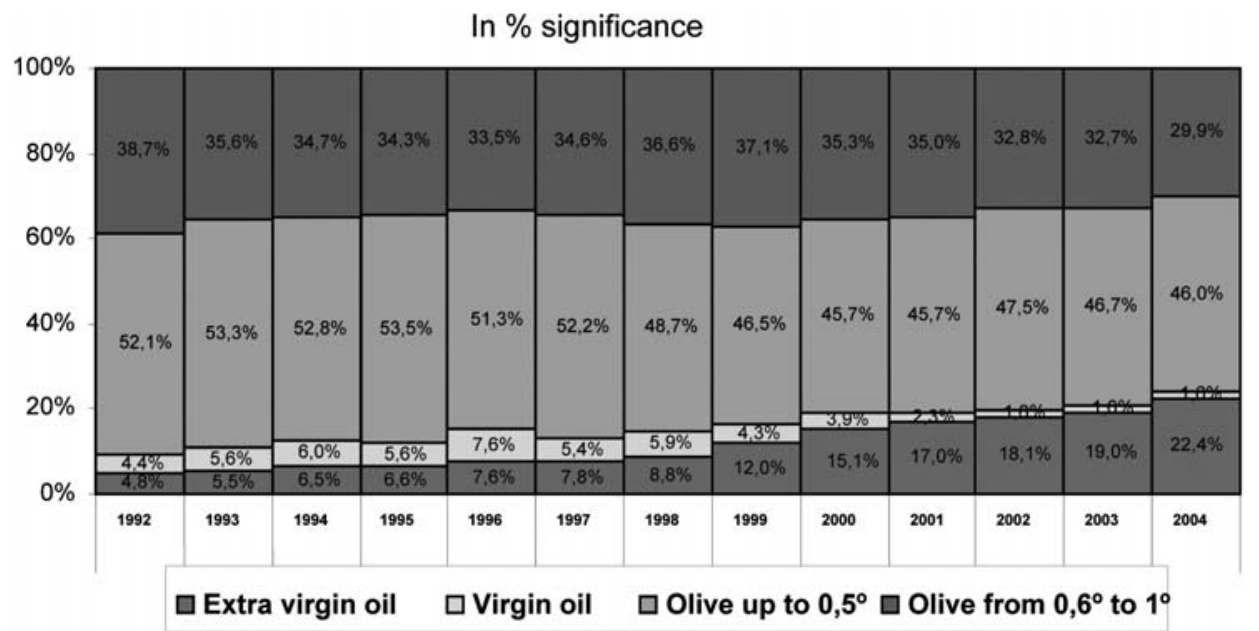

Figure 7

Evolution of the Olive Oil Market in Spain

Source: National Association of Packing and Refining Industries of Edible Oils

determined by the Distribution as manifested by the lowest retail prices in all of Europe. In addition, this consideration is the reason why olive oil is among the items that must be included in the product selection of all food markets in Spain, along with other types of establishments, such as convenience stores, for example.

As far as promotional campaigns are concerned, they are mostly centered on activities at the point of sales, organized by the different brands which exist on the market through negotiations with their distribution chain of choice. Therefore, they are specific activities which correspond to each operator, and are not generic campaigns, except in the case of those promoted by public institutions, which could be, for example, the European Union or the regulating councils of the Designation of Origin.
In what is referred to as advertising, only the leading brands use this tool as a general practice, always seeking to distinguish themselves from other competitors.

\subsubsection{Olive oil in Italy}

As in the case of Spain, the Italian market is a mature market so its volume is very stable and its demand is inelastic.

In reference to categories, they are extra virgin olive oil and olive oil exclusively, without distinguishing any subcategories of the latter.

In Italy, an increase in the consumption of virgin extra can be seen to the detriment of olive oil, and on a much larger scale than in the case of Spain. The consumption of virgin extra olive oil makes up for $75 \%$ of total consumption in Italy (Figure 8 ). In this

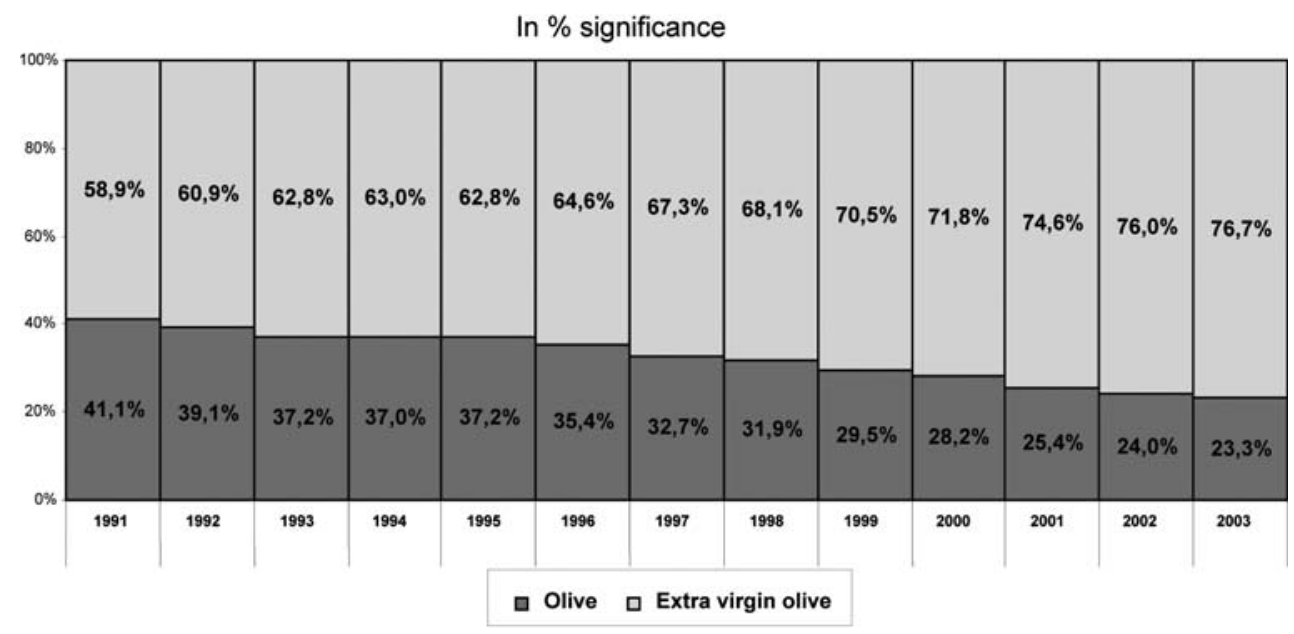

Figure 8

Evolution of the Italian Olive Oil Market

Source: Nielsen 
way, the development of PDO and monovarieties has had a more positive effect on volume in Italy than in Spain.

In this country, the marketing of bottled olive oil is done almost exclusively with glass containers with a small amount of tins. At the same time, this attitude of adding value to the product is reflected in its price, which is somewhere between $15-20 \%$ higher than in Spain.

Nevertheless, this product is still considered of primary necessity in nutrition and its presence is extended throughout all forms of food distribution. In addition, since olive oil is one of Italy's most emblematic food items, it can be found in a variety of establishments, including souvenir shops for tourists.

Finally, promotional campaigns are also centered around the point of sales and advertising is used only by the leading brands.

\subsubsection{Olive oil in Greece}

As a traditionally producing country, the national market for olive oil is also a mature market and volumes and demand for the product have the same characteristics as in Italy and Spain.

However, due to the geographical situation of Greece, made up of a multitude of islands with a mountainous mainland, the logistic function of commercializing olive oil is especially complicated. Distribution is not as well developed as in other European Union countries and therefore, the level of local consumption (self-supplying directly from the pressing mills) is very high.

Regarding commercialized categories, the exceptional quality of Greek olive oil in general, results in the exclusive consumption of extra virgin olive oil, which is sold in glass containers at a price which is situated somewhere between the prices in Spain and Italy.

\subsubsection{Olive oil in Portugal}

The last of the true producing countries in the European Union, prior to the recent increase in the last year, is Portugal, since although France is also a producing country; its production barely covers $5 \%$ of its current consumption.

In contrast to other producing countries in the $\mathrm{EU}$, the olive oil market in Portugal is still growing. Given the fact that the increase in local production is inferior to the increase in consumption, the need to import olive oil (especially from Spain) is becoming greater and greater. This importing of olive oil is done in bulk and then bottled and sold under Portuguese brands.

The commercialized categories are extra virgin olive oil and olive oil. In both cases, the acid level is close to the limits which are stipulated in EU regulations in consideration of a preference for intense, robust flavors.

The oil is normally bottled in glass containers and its prices are similar to those in Spain.

\subsubsection{Olive oil in other countries of the European Union}

The consumption of olive oil in non producing countries of the European Union has more than doubled in the last 15 years, resulting in a Cumulative Annual Growth Ratio of more than two digits. In recent times, no other food product has experienced such a constant increase over such a prolonged period of time.

Once again, this growth can be attributed to the spread of information about the nutritional benefits of the product and in which the promotional campaigns developed by the Directorate-General for Agriculture of the European Commission in the mid to late 90 s have played an important role. One result of these campaigns is the International Consensus Statement about Dietary Fat, the Mediterranean Diet, and Lifelong Good Health 2000, elaborated during the International Conference on the Mediterranean Diet which was held at the Royal College of Physicians in London on 13 and 14 of January, 2000. The document states that "There is increasing scientific evidence that there are positive health effects from diets which are high in fruits, vegetables, legumes, and whole grains, and which include fish, nuts and low-fat dairy products. (...). The traditional Mediterranean Diet, whose principal source of fat is olive oil, encompasses these dietary characteristics."

While promotion has brought about a sampling of the product and this last factor has encouraged further purchase, the Distribution has gone on to include olive oil among its general inventory of products so that today it can be affirmed that olive oil is present in all major food retail centers in Europe.

Commercial categories vary greatly from one country to another. They range from the practically exclusive sale of extra virgin in France to the additional presence of both extra virgin and olive oil in Holland and Belgium. The significance of organic extra virgin olive oil must also be pointed out for certain markets like Germany and the United Kingdom.

As far as its packaging is concerned, olive oil is usually found in glass containers and, in a smaller proportion, in tins. The use of plastic containers is reserved for larger capacities which are used in Food Service.

Due to the fact that this product does not have a high turnover for now, its retail price is situated somewhere above the price in Italy.

\subsection{Olive oil in nonproducing countries. Major markets}

Although almost all the producing countries of the Mediterranean Basin are notable consumers as well, the majority (for example Tunisia, Morocco, Syria or Turkey) are markets which have not yet been modernized as far as Distribution is concerned and most of their consumption is based on local sales. 
Therefore, for this article, more emphasis has been placed on the development of the commercialization of olive oil in some nonproducing countries so that they may serve as a model to follow in other places. These countries are the United States, Japan and Australia in function of the total volume of consumption which has been reached in the first country and in the growth ratios in the last fifteen years in the other two.

\subsubsection{Olive oil in the United States}

At present, the fourth largest market for olive oil worldwide is the American market, having more than doubled its volume in the last 15 years.

There are two fundamental factors which have determined such growth:

The intensity of promotional campaigns: For a long time, the access to olive oil in the United States has depended on Italian and Hispanic ethnic food markets. Nevertheless, the initiation of promotional campaigns on behalf of the International Olive Oil Council as well as other organisms such as the Instituto de Comercio Exterior (in the case of Spain) have made an immediate impact on the increase in consumption in the United States, which is illustrated in Figure 9.

Growing concerns over obesity and heart disease: The different health departments in the United States have determined that obesity is to be considered an epidemic, making it responsible for a number of diseases, among which heart disease is the most serious and one of the leading causes of death in this country. This has progressively led to the promotion of the use of fats from vegetables in place of animal fats at the beginning of the 90s. After that, they have gone on to establish the virtues of vegetable oils (in liquid form) as opposed to hydrogenized fats (in solid form) towards the end of that same decade. Finally, they currently point out the benefits of the consumption of vegetable oils which are rich in monounsaturated

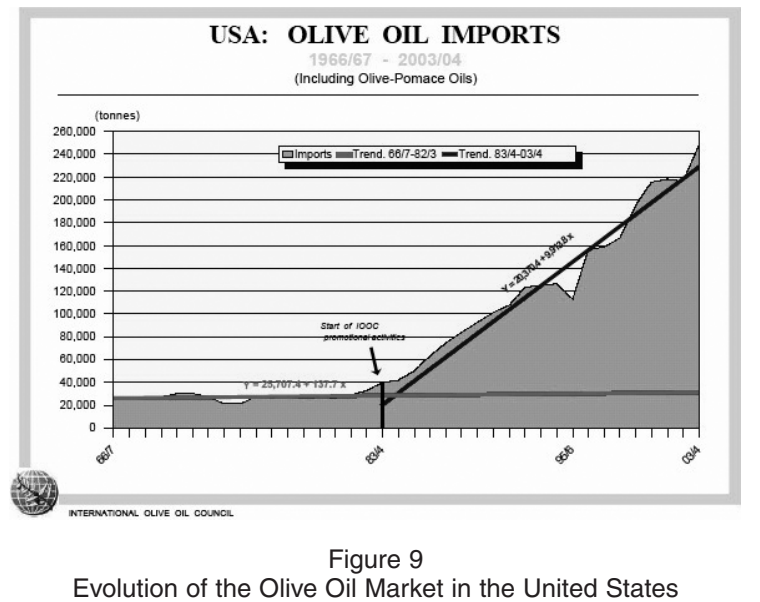

Evolution of the Olive Oil Market in the United States
Source: International Olive Oil Council (I.O.O.C.) acids (such as olive oil) as opposed to those which are rich in saturated acids. Therefore, it is especially relevant that the U.S. Food and Drug Administration (FDA), on the first of November, 2004, would make a "qualified health claim for monounsaturated fat from olive oil and reduced risk of coronary heart disease" on the labels of olive oil and on certain foods which contain olive oil. Such an allegation on the nutrition and health benefits of a conventional food item, the third and last authorized by the FDA since the process for the inclusion of such claims began in 2003, consists of the following:

"Limited and not conclusive scientific evidence suggests that eating about 2 tablespoons (23 grams) of olive oil daily may reduce the risk of coronary heart disease due to the monounsaturated fat in olive oil. To achieve this possible benefit, olive oil is to replace a similar amount of saturated fat and not increase the total number of calories you eat in a day. One serving of this product [Name of food] contains [x] grams of olive oil."

All of this has contributed to an increase in the presence of olive oil in food establishments, which, together with the elevated price set for this product (between $60 \%$ and $80 \%$ higher than in Spain) has resulted in olive oil having the highest selling value in retail distribution for the category of pourable oils. ${ }^{2}$

Approximately $3 / 4$ of its commercialization is found in glass containers, with the rest being sold in tins.

Finally, in reference to olive oil types, in addition to extra virgin and olive oil, the type "extra light" can be found. This oil consists of $95 \%-98 \%$ refined olive oil combined with the remaining $5 \%-2 \%$ virgin olive oil.

\subsubsection{Olive oil in Australia}

The process of marketing olive oil in Australia has followed a similar path to that for the United States (Figure 10), with even more impressive results since

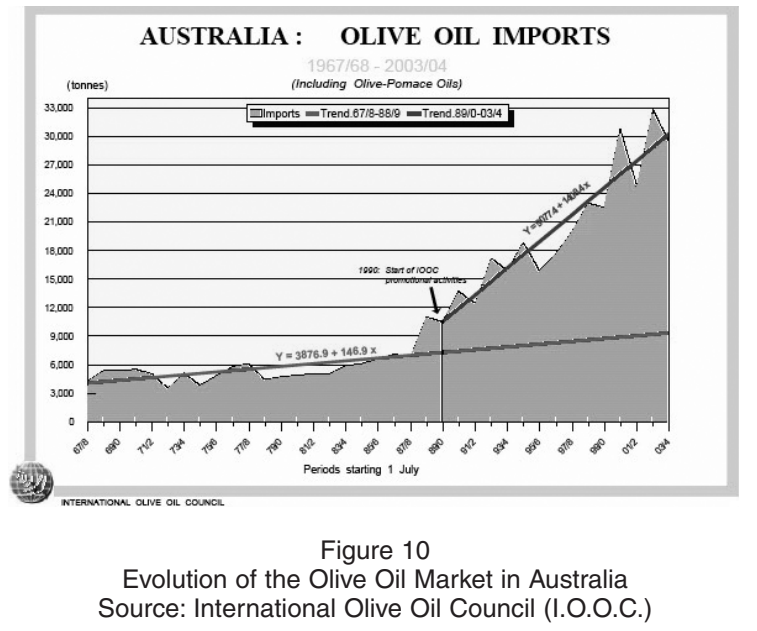

${ }^{2}$ The North American Retail Olive Oil Market. The Chairman's Report, North American Olive Oil Association, NewYork, July 8, 2005. 
the consumption of this product has almost tripled in the last 15 years.

Nevertheless, there are some material differences in prices as well as products with respect to the American market.

Regarding products, olive oil makes up for almost $70 \%$ of total consumption, while extra virgin represents the remaining $30 \%$. The traditional format has been the tin, although recently, glass containers seem to be more and more common.

The price of olive oil in Australia is situated below the American price but still approximately $40-50 \%$ higher than Spanish prices.

\subsubsection{Olive oil in Japan}

Another market which the IOOC has considered a priority when it comes to its promotional activities is Japan. In this country, the increase in the consumption of olive oil has been the highest worldwide after registering a TACC of $17.4 \%$ in the last 15 years. As can be seen in Figure 11, also in the case of the Japanese market, remarkable results have been brought about from the same promotional activities carried out by the international organism I.O.O.C.

In reference to commercial categories, olive oil and extra virgin share the market in a practically identical distribution, with the tin being the most common format for Food Services while glass containers are found in the retail sector.

Finally, Japanese prices may be the highest in the world, resulting from the high consideration in which Japanese consumers hold the product.

\subsection{Olive pomace oil}

At the beginning of the $90 \mathrm{~s}$, the introduction of a two-phase system in olive pressing mills, especially

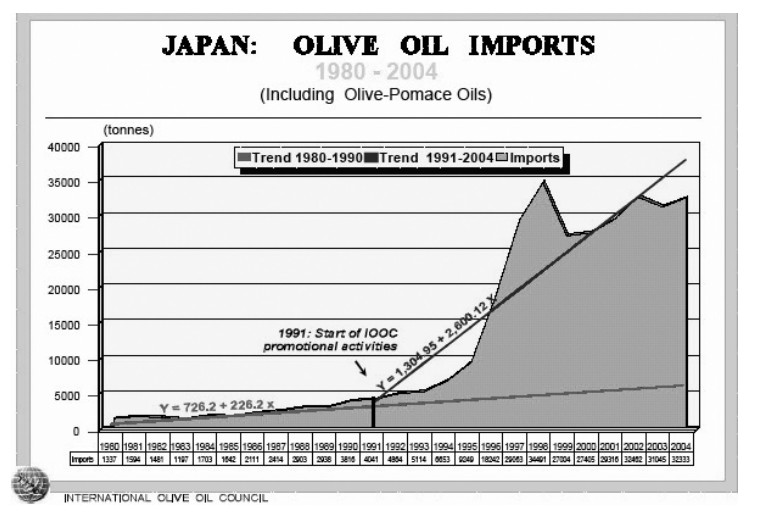

Figure 11

Evolution of the Olive Oil Market in Japan Source: International Olive Oil Council (I.O.O.C.)
Spanish mills, was begun with the objective of solving the serious environmental problem caused by the elimination of vegetation waters. This has brought about a significant loss in the availability of olive pomace oil.

For a long time, olive pomace oil been used primarily in the Food Service Industry and especially in the Food Canning Industry throughout Europe after the EU began promoting the use of olive oils for the elaboration of certain canned goods by means of economic restitutions. However, it must be pointed out that after November 1, 2005, the Common Market Organization for the olive oil and table olive sector $^{3}$ comes into effect and does not contemplate such economic aids.

It must also be pointed out that the olive pomace oil has been a significant part of the market in Europe (Spain and Portugal) as well as in other countries (Middle East). Nevertheless, Spanish health authorities declared an alert concerning olive pomace oil in July, 2001 because of the presence of benzopirene in the oil, even though there was no existing national or European legislation concerning the issue at the time. This alert caused a drop in the national market as well as the traditional Arabic markets which has never been recovered and current volumes are less than a third of what they were before the "pomace oil crisis"

\section{Future Challenges}

One of the objectives that the olive oil sector must reach within a short period of time is the absolute traceability of bottled olive oil. Internal traceability as well as "under water" traceability are practically resolved, especially on the part of large industry. However, for the traceability of providers or "above water", which would permit access to valuable information relating to raw materials (olive oils) which producers supply to the bottling industry. This type of traceability would facilitate knowledge about varieties of olives, sanitary treatments applied at the trees, geographical location, incidents relating to climate, irrigation, pruning, insect attacks, date and collection system, the mill where the olive was pressed, etc.

From a quality point of view, the improvement in the olive collecting system requires separate the fruit picked up off the ground from the one picked directly from the tree, to obtain extra virgin olive oil with greater sensory quality.

Finally, from the safety and food hygiene stand point, one important aspect of a product like olive oil, more and more valuable to consumers as a healthy product, prototype of the Mediterranean diet, would be to achieve an olive oil which is made without any contaminating chemicals (PAHs, heavy

${ }^{3}$ EU Regulation n.827/04 which includes the previously mentioned Common Market Organization, and EU Regulation n. 864/04, which introduces necessary changes in the Community Agricultural Policy (CAP) required for the enforcement of the OCM. 
metals, pesticides, etc.). With respect to the PAHs, Regulation (EU) 208/2205 which came into effect on April 1, 2005, establishes a maximum content of benzopirene in vegetable oils at $2 \mu \mathrm{g} / \mathrm{Kg}$, and therefore regulates the presence of such contaminants. Nevertheless, with respect to pesticide residuals, Spanish olive oil, which makes up more than $50 \%$ of the world's production, is practically the only one in the Mediterranean basin containing considerable levels of certain pesticides. This fact presents a problem with the marketing of a product sold for its nutritional benefits and for its healthy image.

This problem is even more serious when considering that Spain is precisely the country which is progressively increasing its quota of extra virgin olive oil consumption. On the other hand, a large part of the Spanish production is shipped in bulk to other European Union countries where it is used as habitual ingredient in a large variety of brand names.

Therefore, fitosanitary treatment must be carried out in a way which does not result in the presence of contaminants in olive oils. On the other hand, it would be advisable to establish legal guidelines which regulate its presence in olive oil.

\section{REFERENCES}

ANIERAC. 2005. Estadísticas de las ventas de aceites envasados con marca en España en el período de enero a diciembre de 2004. Asociación Nacional de Industriales Envasadores y Refinadores de Aceites Comestibles (ANIERAC). Madrid, February $4^{\text {th }}$.

CE Rules. 2002. $n^{\circ}$ 178/2002 del Parlamento Europeo y del Consejo de 28 de enero de 2002, por el que se establecen los principios y los requisitos generales de la legislación alimentaria, se crea la Autoridad Europea de Seguridad Alimentaria y se fijan procedimientos relativos a la seguridad alimentaria. Official Journal of the European Communities $n^{\circ} \mathrm{L} 031$ February, $1^{\text {st }}$.

CE Rules. 2005. 63/Doc. N.3 Corr.1. Consejo Oleícola Internacional (IOOC), 15/11/2005.

Francisco Polledo JJ. 2002. Gestión de la Seguridad Alimentaria. Madrid A. (Ed.) Ediciones Mundi-Prensa. Madrid.

Madrid A. 1989. Manual de Industrias Alimentarias. A. Madrid Vicente Ediciones. Madrid.

MAPA. 2004. La Alimentación en España 2003. Ministerio de Agricultura, Pesca y Alimentación (MAPA). Madrid.

Paine FA., Paine HY. 1994. Manual de envasado de alimentos. A. Madrid Vicente Ediciones. Madrid.

Recibido: Septiembre 2005 Aceptado: Noviembre 2005 